\title{
Symmetrical and bilateral basal ganglia calcification. Case series and literature review
}

\author{
Amado Jiménez-Ruiz', Omar Cárdenas-Sáenz' and José Luis Ruiz-Sandoval \\ ${ }^{1}$ Internal Medicine; ${ }^{2}$ Neurology, Hospital Civil de Guadalajara Fray Antonio Alcalde, Guadalajara, Jalisco, Mexico
}

\begin{abstract}
Introduction: Symmetric, bilateral basal ganglia calcification is rare finding that sometimes occurs asymptomatically. Its prevalence increases with age, and the most affected site is the globus pallidus. Report of cases: $A$ series of seven cases with clinical and imaging diagnosis of basal ganglia calcification, recorded during the 2012 to 2016 period at the Department of Internal Medicine of the Hospital Civil de Guadalajara "Fray Antonio Alcalde, is presented. Most common clinical presentation was with altered alertness, headache and seizures. There was one case with movement disorders; there were no cases identified with dementia or tetany. Conclusion: Ganglia calcification can be associated with age-related neurodegenerative changes, but it can be an initial manifestation of a variety of systemic pathologies, including disorders of the calcium metabolism, intoxication by different agents, and autoimmune and genetic diseases. Correlation of typical imaging findings with clinical manifestations and laboratory results should be established to reach a definitive judgment.
\end{abstract}

KEY WORDS: Basal ganglia calcification. Fahr's syndrome. Hypoparathyroidism. MELAS syndrome.

\section{Introduction}

Basal ganglia calcification is an unspecific finding observed in $1 \%$ of all performed cranial tomographies; ${ }^{1}$ for its study, it is classified as physiological and pathological. The former is associated with aging, and the latter with metabolic or autoimmune disorders or primary neurodegenerative diseases, especially in young patients. Most common causes include disorders of the calcium metabolism, especially hypoparathyroidism and pseudohypoparathyroidism. ${ }^{2}$ However it can also be found associated with exposure to certain toxic substances (led, carbon monoxide), with intracranial radiation and genetic neurodegenerative conditions. Idiopathic basal ganglia calcification or Fahr's disease is a rare condition that can have a specific inheritance pattern or occur sporadically.

In this investigation, seven cases that were admitted to the Hospital Civil de Guadalajara Fray Antonio Alcalde internal medicine department within a period of 4 years, with diagnosis established by imaging, are described.

\section{Methods}

Medical records of patients with a basal ganglia calcification diagnosis established by findings on a cranial computed axial tomography, attended to between 2012 and 2016, were reviewed. The following inclusion criteria were considered:

- Computed axial tomography findings consistent with basal ganglia calcification.

- Availability of etiologic diagnosis by paraclincal tests.

Cases with incomplete studies at admission and therefore with inconclusive diagnosis were excluded.

\section{Results}

The patients with basal ganglia calcification imaging diagnosis by computed axial tomography were 7 , two with concomitant cerebellar and subcortical calcification; 3 of all 7 were males; average age at presentation was 38 years.
Date of reception: 06-02-2016

Date of acceptance: 26-04-2016

DOI://dx.doi.org/10.24875/GMM.M18000137
Gac Med Mex. 2018;154:210-214

Contents available at PubMed www.gacetamedicademexico.com 
Table 1. Clinical presentation, tomographic findings, laboratory tests and etiologic diagnosis in 7 patients with basal ganglia calcification

\begin{tabular}{|c|c|c|c|c|c|c|c|c|c|}
\hline Case & Gender & Age & $\begin{array}{l}\text { Basal ganglia } \\
\text { calcification }\end{array}$ & $\begin{array}{l}\text { Cerebellar } \\
\text { calcification }\end{array}$ & $\begin{array}{l}\text { Subcortical } \\
\text { calcification }\end{array}$ & Clinical presentation & Findings & Etiologic diagnos & sis \\
\hline 1 & M & 51 & Present & Present & Present & $\begin{array}{l}\text { Alertness state } \\
\text { alteration, headache, } \\
\text { seizures, hemiparesis }\end{array}$ & $\begin{array}{l}\text { Hyperlactemia, } \\
\text { diabetes mellitus, } \\
\text { hypoacusis, muscle } \\
\text { biopsy with ragged } \\
\text { red fibers in Gomori } \\
\text { trichome staining }\end{array}$ & MELAS & 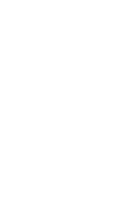 \\
\hline 2 & M & 46 & Present & Absent & Absent & $\begin{array}{l}\text { Alertness state } \\
\text { alteration, seizures }\end{array}$ & $\begin{array}{l}\text { Calcium } 3.6 \mathrm{mg} / \mathrm{dL} \\
(8.5-10.1), \\
\text { Phosphate } 8.3 \mathrm{mg} / \mathrm{dL} \\
\text { (2.4-4.5), } \\
\text { PTH 126 pg/mL } \\
(4.6-58.1)\end{array}$ & Pseudohypoparat & 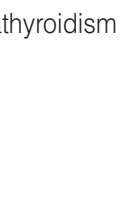 \\
\hline 3 & M & 62 & Present & Present & Present & $\begin{array}{l}\text { Seizures, bilateral } \\
\text { cataract }\end{array}$ & $\begin{array}{l}\text { Calcium } 6.1 \mathrm{mg} / \mathrm{dL} \\
(8.5-10.1), \\
\text { Phosphate } 5 \mathrm{mg} / \mathrm{dL} \\
(2.4-4.5) \\
\text { PTH } 1 \mathrm{pg} / \mathrm{mL} \\
(4.6-58.1)\end{array}$ & Hypoparathyroidis & 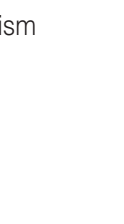 \\
\hline 4 & $F$ & 34 & Present & Absent & Absent & $\begin{array}{l}\text { Hemiparesis and } \\
\text { vertigo }\end{array}$ & $\begin{array}{l}\text { Normal calcium and } \\
\text { phosphate } \\
\text { Normal PTH }\end{array}$ & Fahr & 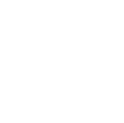 \\
\hline 5 & $F$ & 17 & Present & Absent & Absent & $\begin{array}{l}\text { Alertness state } \\
\text { alteration }\end{array}$ & $\begin{array}{l}\text { Positive antinuclear } \\
\text { antibodies }\end{array}$ & $\begin{array}{l}\text { Systemic Lupus } \\
\text { Erythematosus }\end{array}$ & $\frac{1}{2}$ \\
\hline 6 & $\mathrm{~F}$ & 20 & Present & Absent & Absent & Seizures & $\begin{array}{l}\text { Hyperlactemia, } \\
\text { diabetes mellitus, } \\
\text { hypoacusis, muscle } \\
\text { biopsy with ragged } \\
\text { red fibers in Gomori } \\
\text { trichome staining }\end{array}$ & MELAS & 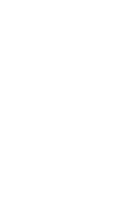 \\
\hline 7 & $\mathrm{~F}$ & 42 & Present & Absent & Absent & $\begin{array}{l}\text { Alertness state } \\
\text { alteration }\end{array}$ & $\begin{array}{l}\text { Hyperlactemia, } \\
\text { diabetes mellitus, } \\
\text { hypoacusis, muscle } \\
\text { biopsy with ragged } \\
\text { red fibers in Gomori } \\
\text { trichome staining }\end{array}$ & MELAS & 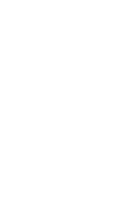 \\
\hline
\end{tabular}

Most common clinical manifestations were alertness state alteration, headache and seizures. Clinical manifestations, tomographic findings, laboratory tests and etiologic diagnosis are described in table 1. In table 2, most common radiological and clinical alterations are detailed. Finally, table 3 lists the main causes of basal ganglia calcification. There was one case with movement disorder; no one had dementia or tetany, which are differential diagnoses according to the etiology.

\section{Discussion}

Together with the cerebellum, the motor thalamus and frontal cortex constitute a complex system that guarantees organization and execution of normal patterns of movement. ${ }^{3}$
Table 2. Most common radiological and clinical alterations in 7 patients with basal ganglia calcification

\begin{tabular}{lc|c|c}
\hline & $\mathbf{n}$ & $\%$ \\
\hline Cerebellar calcifications & 2 & & $\%$ \\
Subcortical calcifications & 3 & 28 \\
Alertness state alteration & 4 & 2 \\
Seizures & 4 & 57 \\
Headache & 1 & & 57 \\
Motor disorders & 2 & & 14 \\
Parkinsonism & 1 & & 28 \\
\hline
\end{tabular}

Symmetric and bilateral calcification has been described in association with different disorders: toxic (by carbon monoxide or led), of the calcium 
Gaceta Médica de México. 2018;154

Table 3. Main causes of basal ganglia calcification

\begin{tabular}{|c|c|c|c|c|}
\hline Etiology & Example & Etiology & Example & \\
\hline Idiopathic & $\begin{array}{l}\text { - Aging } \\
\text { - Fahr's disease }\end{array}$ & Toxic & $\begin{array}{l}\text { - Carbon monoxide } \\
\text { - Led } \\
\text { - Mineralizing microangiopat } \\
\text { - Anticonvulsant treatment }\end{array}$ & thy \\
\hline Metabolic & $\begin{array}{l}\text { - Hypoparathyroidism } \\
\text { - Pseudohypoparathyroidism }\end{array}$ & Miscellaneous & $\begin{array}{l}\text { - Systemic lupus erythemato } \\
\text { - Chemotherapy/radiotherap }\end{array}$ & sus \\
\hline Hereditary & $\begin{array}{l}\text { - Mitochondrial diseases (MELAS/MERRF) } \\
\text { - Aicardi-Goutières syndrom } \\
\text { - Cockayne Syndrome } \\
\text { - Down syndrome }\end{array}$ & & & $\begin{array}{l}\text { (c) } \\
\frac{1}{\frac{1}{4}}\end{array}$ \\
\hline
\end{tabular}

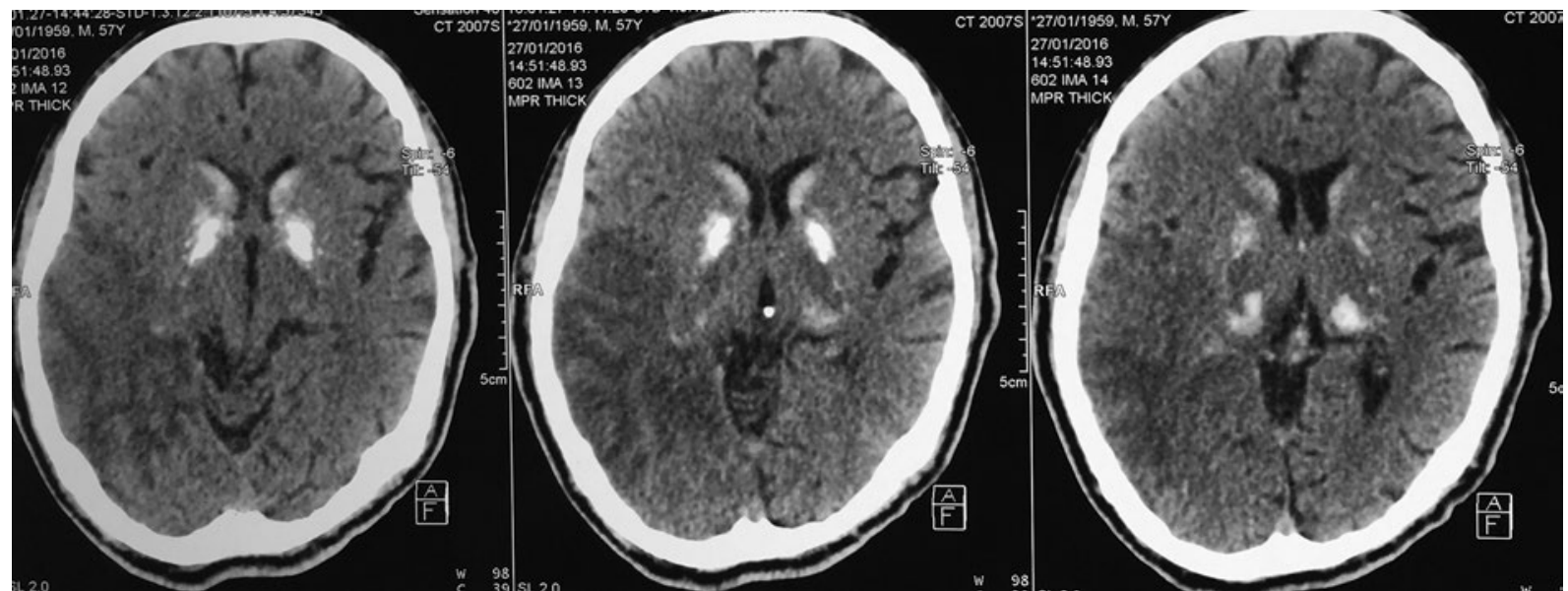

Figure 1. Case 1. MELAS syndrome. Bilateral calcifications in basal ganglia and parieto-occipital hypodensity consistent with stroke-like by magnetic resonance imaging.

metabolism (hypoparathyroidism, hyperparathyroidism, pseudohypoparathyroidism), anoxic-ischemic encephalopathy, autoimmune diseases (systemic lupus erythematosus) and genetic neurodegenerative conditions (MELAS syndrome, Cockayne disease, Hallervorden-Spatz disease). When there is no identifiable cause it is called Fahr's disease. ${ }^{4,5}$

Calcified ganglia are generally incidentally detected in a computed tomography. ${ }^{6}$ Physiological intracranial calcifications are observed in approximately 0.3 to $1.5 \%$ of cases, are incidentally identified by neuroimaging and are usually asymptomatic. In a cases series of 2012, Abdelrahman retrospectively reviewed 1040 cranial tomographies, with 552 corresponding to males; he found basal ganglia calcification in $1.25 \%$ $(0.72 \%$ in males and $1.85 \%$ in females; $\mathrm{OR}=2.57$ [0.72-9.98]; RR = $2.55[0.79-8.21] ; p=0.1) .6,7$

Being part of the aforementioned entities, most cases exhibit symptoms that range from movement disorders (parkinsonism, chorea, athetosis), alertness state alterations, headache and seizures to syndromes such as upper motor neuron and neuropsychiatric syndromes. ${ }^{8,9}$
The cause whereby the described patients had basal ganglia calcification was different in each one; according to initial history and physical examination, the specific protocol was followed to arrive to definitive diagnosis.

MELAS syndrome is caused by different mitochondrial DNA point mutations of maternal inheritance; the most common (in 80 to $85 \%$ ) is the one in tRNA A3243G position of maternal DNA. First description of MELAS syndrome was made by Pavlakis et al. in 1984, who defined it as one of the multi-systemic mitochondrial syndromes related to stroke before 40 years of age, encephalopathy characterized by focal or generalized seizures, lactic acidosis and ragged red fibers in muscle biopsy. Diabetes mellitus, as well as bilateral hypoacusis are common findings. Approximately $30 \%$ of patients with MELAS exhibit basal ganglia calcification. ${ }^{10-12}$

An example of MELAS syndrome can be appreciated in figure 1.

Hypoparathyroidism is an endocrine deficiency characterized by low calcium serum levels, elevated phosphorus levels and absence or inappropriately low 


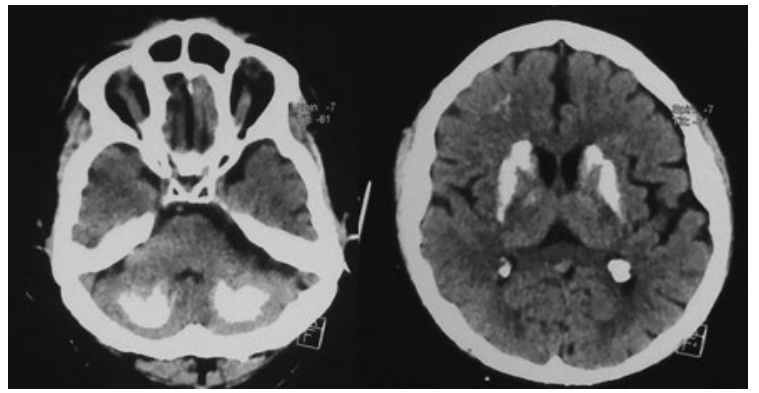

Figure 2. Case 3. Pseudohypoparathyroidism. Bilateral, symmetric calcifications in basal ganglia and cerebellar hemispheres.

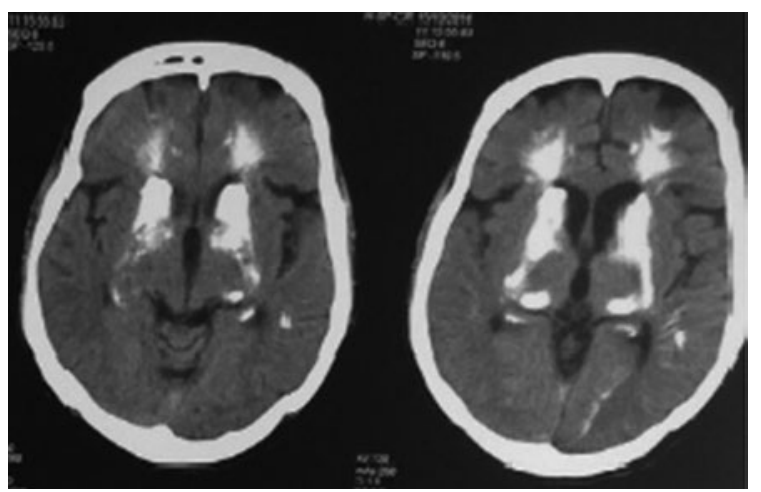

Figure 3. Case 3. Hypoparathyroidism. Bilateral, symmetric calcifications in basal ganglia, as well as subcortical.

serum levels of parathyroid hormone (PTH). It can be accompanied by seizures secondary to low calcium levels or to symmetrical and bilateral calcification of different brain structures, such as basal, subcortical or cerebellar ganglia. ${ }^{13}$

Pseudohypoparathyroidism is a rare heterogeneous hereditary disorder, characterized by hypocalcemia-hyperphosphatemia with elevated plasma PTH in the absence of renal damage. It was first described by Albright; in some case series, extra-skeletal calcifications have been identified in up to $84 \%$ of patients, including those of basal ganglia. ${ }^{13-15}$

Pseudohypoparathyroidism and hypoparathyroidism tomographic findings examples can be seen in figures 2 and 3.

Fahr's disease consists of symmetric calcifications, mainly localized in basal ganglia and the cerebellum, which is associated with varied neurological disorders, with the most common including extrapyramidal-type movement disorders (with predominance of parkinsonism, although choreoathetosis, dystonia, tremor, orofacial dyskinesia and paroxysmal chorea is also found), dementia and psychiatric alterations; in few occasions, sensory disturbances are associated. The pathophysiological mechanism resides in the deposit of calcium and other minerals at the globus pallidus, putamen, corona radiata, thalamus, cerebellar dentate nuclei and hemispheric and cerebellar white matter; these calcium deposits are formed surrounding a polysaccharide nest that is primarily produced on arteriole and capillary walls. For its diagnosis, demonstrating affected first-line relatives is necessary, as well as ruling out the aforementioned disorders. ${ }^{16,17}$

Systemic lupus erythematous is a common autoimmune condition that affects young women, and occurs with joint, pleuropulmonary, cutaneous, hematological, renal and neurological symptoms. As for its association with basal ganglia calcification, the pathophysiological mechanism is not fully understood, although different theories try to explain its onset. ${ }^{18,19}$

\section{Diagnostic algorithm}

Laboratory tests should include calcium, phosphorus and PTH levels to rule out parathyroid disorder.

If observed together with hypodensity suggesting stroke, especially in young patients, serum lactate and cerebrospinal fluid should be included, as well as muscle biopsy with Gomori trichome staining looking for ragged red fibers in order to rule out mitochondrial disease. In young patients with multiple organ involvement, antinuclear antibodies should be requested to rule out neurolupus; if results are negative, it can be classified as idiopathic disorder.

\section{Conclusion}

Bilateral and symmetrical basal ganglia calcification is a rare finding that sometimes causes no symptoms. Its prevalence increases with age, and the most affected site is the globus pallidus. Most common causes reported in the world literature are Fahr's disease and calcium metabolism disorders; however, differential diagnosis is broad. A correlation of typical imaging findings with clinical manifestations and laboratory results should be established in order to arrive to a definitive diagnosis.

\section{References}

1. Rumboldt Z, Castillo M, Huang B, Huang B, editores. Brain imaging with MRI and CT: An image pattern approach. EE. UU: Cambridge University Press; 2012.

2. Radaideh AM, Jaradat DM, Haddad FH. Prevalence of incidental basal ganglia calcification on routine brain computed tomography. RMJ. 2012;37 (1):6-8

3. Hathout GM. Clinical Neuroradiology. A case-based approach. Inglaterra: Cambridge University; 2009.

4. Manyam, BV, Walters AS, Narla KR. Bilateral striopallidodentate calcinosis: clinical characteristics of patients seen in a registry. Mov Disord. 2001;16 (2):258-264 
5. Benke T, Karner E, Seppi K, Delazer M, Marksteiner J, Donnemiller E. Subacute dementia and imaging correlates in a case of Fahr's disease. J NeurolNeurosurgPsychiatry. 2004;75 (8):1163-1165.

6. Eskandary H, Sabba M, Khajejpour F, Eskandari M. Incidental findings in brain computed tomography scans of 3000 head trauma patients Surg Neurol. 2005;63 (6):550-553

7. Daghighi MH, Rezaei V, Zarrintan S, Pourfathi H. Intracranial physiolog ical calcifications in adults on computed tomography in Tabriz, Iran Folia Morphol (Warsz). 2007;66 (2):115-119.

8. Lauterbach EC, Cummings JL, Duffy J, Coffey CE, Kaufer D, Lovell M et al. Neuropsychiatric correlates and treatment of lenticulostriatal diseases: a review of the literature and overview of research opportunities in Huntington's, Wilson's, and Fahr's diseases.A report of the ANPA Committee on Research. J Neuropsychiatry Clin Neurosci. 1998;10 (3):249-266

9. Johnson JM, Legesse B, Camprodon JA, Murray E, Price BH. The clinical significance of bilateral basal ganglia calcification presenting with mania and delusions. J Neuropsychiatry Clin Neurosci. 2013 25 (1):68-71.

10. Abe K, Yoshimura H, Tanaka H, Fujita N, Hikita T, Sakoda S. Comparison of conventional and diffusion-weighted MRI and proton MR spectroscopy in patients with mitochondrial encephalomyopathy, lactic acidosis, and stroke-like events. Neuroradiology. 2004;46 (2):113-117.
11. Cano A, Romero Al, Bravo F, Vida JM, Espejo S. Síndrome MELAS: hallazgos neurorradiológicos. Radiología. 2002;44 (2):69-74.

12. Bianchi MC, Tosetti M, Battini R, Manca ML, Mancuso M, Cioni G, et al. Proton MR spectroscopy of mitochondrial diseases: analysis of brain metabolic abnormalities and their possible diagnostic relevance. Am J Neuroradiol. 2003;24 (10):1958-1966.

13. Basak RC. A case report of basal ganglia calcification; a rare finding of hypoparathyroidism. Oman Med J. 2009;24 (3):220-222.

14. Wong E, Dahl M. Basal Ganglia Calcification in idiopathic hypoparathyroidism. BCMJ. 2013;55 (10):462-465

15. Rastogi R, Beauchamp NJ, Ladenson PW. Calcification of the basal ganglia in chronic hypoparathyroidism. JClin Endocrinol Metab. 2003;88(4):1476-1477.

16. Mufaddel AA, Al-Hassani GA.Familial idiopathic basal ganglia calcification (Fahr's disease).Neurosciences (Riyadh). 2014;19 (3):171-177.

17. Shahidi GA, Safdarian M. Fahr disease: idiopathic basal ganglia calcification. Iran J Neurol. 2017;16 (1):53-54.

18. Contreras P, Elso MJ, Ramírez DC, Cartier L. Pseudo-infarto cerebral como primeramanifestación de un MELAS tardío. Rev Chil Neuro-Psiquiat. 2008;46 (1):35-42.

19. Benavente E, Paira S, Roverano S, Saredo G. Encefalitis con estatus convulsivo localizado en una paciente con lupus eritematoso sistémico. Reumatol Clin. 2013;9 (2):123-127. 